\section{Submitted: Comparing intrapartum ultrasound and clinical Accepted: 24.06.2019 examination in the assessment of fetal head position in African women}

Published: 31.12.2019

\section{Keywords}

ultrasound, digital vaginal examination, head position, labor

\author{
Yaw A. Wiafe ${ }^{1,2}$, Bill Whitehead², Heather Venables ${ }^{1}$, Edward T. Dassah³ \\ ${ }^{1}$ College of Health and Social Care, University of Derby, Derby, UK \\ ${ }^{2}$ Department of Medical Diagnostics, College of Health Sciences, Kwame Nkrumah \\ University of Science and Technology, Kumasi, Ghana \\ ${ }^{3}$ Department of Obstetrics and Gynecology, Komfo Anokye Teaching Hospital and School \\ of Public Health, Kwame Nkrumah University of Science and Technology, Kumasi, Ghana \\ Correspondence: Yaw A. Wiafe, Department of Medical Diagnostics, Kwame Nkrumah University \\ of Science and Technology, Kumasi, Ghana; e-mail:wadart1@gmail.com
}

DOI: $10.15557 / J o U .2019 .0037$

\begin{abstract}
Introduction: We aimed to examine the agreement between intrapartum ultrasound and digital vaginal examination in assessing the occiput position in black African women who were in the first stage of labor and to evaluate the influence of ruptured membranes on this agreement. Material and method: This was a cross-sectional study conducted in a teaching hospital in Ghana. Transabdominal ultrasound determination of the fetal head position was compared with digital vaginal examination of women in labor. The agreement between the two methods was examined with Cohen's kappa statistics. Results: Altogether, 196 women in active labor were studied. The fetal head position could not be determined by digital vaginal examination in 62 cases $(32 \%)$ while ultrasound could determine all. Moderate agreement (kappa $=0.4)$ was obtained in the 134 cases determined by both methods. Agreement on the occiput posterior position was very low $(\mathrm{kappa}=0.1)$. Agreement on the occiput posterior position was not significantly different in ruptured versus intact membranes. Conclusion: This study shows poor agreement between ultrasound and digital VE on the occiput posterior position in black African women who were in the first stage of labor. Again, over 85\% of fetal head positions that could not be determined by digital vaginal examination were occiput transverse and posterior positions. This confirms that digital vaginal examination has difficulty in detecting malpositions, with no significant influence of intact or ruptured membranes. Ultrasound is therefore more useful than digital vaginal examination whenever malposition is suspected in the first stage of labor.
\end{abstract}

\section{Introduction}

The fetal head position plays an important role in the mode of delivery and is one of the known predictors of labor outcome. Particularly, the persistent occiput posterior position might be associated with prolonged labor and operative delivery ${ }^{(1-3)}$. Undiagnosed occiput posterior positions increase the risk of perineal lacerations and neonatal injuries in the process of delivery ${ }^{(4)}$. An accurate method for determining the occiput position is therefore useful in assessing the progress of labor.

Studies conducted in different populations have shown that ultrasonography is more accurate than digital vaginal examination (VE) in assessing the occiput position in labor ${ }^{(5)}$. A systematic review of these various studies found no such study conducted in a black African population ${ }^{(5)}$. Due to variations in the pelvic architecture of women from 
different geographical locations ${ }^{(6-8)}$, and the relatively higher incidence of malposition and malpresentation in black women compared to whites ${ }^{(9)}$, a context-specific study on ultrasound versus digital VE was needed on the assessment of the occiput posterior position.

Again, existing studies mainly assessed the overall agreement between ultrasound and digital VE which considered all fetal head positions, without being specific about statistical agreement on the occiput posterior position, which is the most important reason for the examination.

In addition, while existing studies have shown that there is significant agreement between ultrasound and digital VE in the second stage of labor ${ }^{(5)}$, which coincides with when membranes have mostly ruptured, the influence of ruptured membranes on the agreement between ultrasound and digital VE was not very clear.

Consequently, the primary objective of this prospective study included assessing the overall agreement between ultrasound and digital VE in a black African population, and to analyze the agreement on the occiput posterior position. The secondary objective was to assess the influence of ruptured membranes on this agreement.

\section{Material and methods}

This cross-sectional study was carried out at the labor and delivery ward of Komfo Anokye Teaching Hospital (KATH) in Kumasi, Ghana. Women who were eligible for inclusion were those who had received antenatal care at KATH, had singleton pregnancy, cephalic presentation, were in spontaneous labor and had given consent to participate in the study. Women with multiple pregnancy, breech presentation, macrosomia, intrauterine growth restriction, known fetal abnormality, previous cesarean section, and those with obstetrical comorbidities, such as hypertensive disorders in pregnancy and diabetes in pregnancy were all excluded from the study.

Recruitment of potential study participants began during the antenatal period. Women receiving antenatal care at KATH who met the inclusion criteria, had no contraindications to vaginal delivery and were in their third trimester, were approached individually by a member of the research team. After explaining to them the purposes and benefits of the study, they were invited to participate and written informed consent was obtained. The signed informed consent form was then attached to the antenatal record booklet of all consenting potential study participants. The women were then approached again during labor at KATH.

The criteria for labor at KATH are painful uterine contractions accompanied by cervical effacement and dilatation. Women with cervical dilatation of at least $4 \mathrm{~cm}$ are usually admitted to the labor ward. Digital VE is performed for every woman during admission. Depending on the cervical dilatation, subsequent digital
VE is performed every 4 hours, or earlier if clinically indicated. During labor, all potential study participants were again approached individually by a member of the research team, who asked them about their interest in participating in the study. Women who reaffirmed their consent to participate were then recruited. Women were recruited consecutively until the desired sample size was attained. Except for the intrapartum ultrasound scan, which was done for the study participants, all other processes of labor were assessed and monitored as is usually done. Ultrasound examination to determine the fetal head position was arranged to coincide with the next digital VE, in accordance with the protocols of the labor ward at KATH.

Digital VE was performed by the attending obstetrician, who determined the occiput position along with other parameters for assessing the progress of labor. Only obstetricians with at least 5 years of experience in intrapartum care were allowed to determine the occiput position.

Immediately after performing digital VE, a transabdominal ultrasound scan was performed by an experienced sonographer, who had over 10 years of experience in obstetric ultrasound. The sonographer was blinded from the digital VE findings of the attending obstetrician. The ultrasound scans were performed with a mobile ultrasound unit (P 300, Siemens-Acuson, Italy), using a 2-5 MHz curvilinear transducer. Each participant had one ultrasound examination performed for the study.

The transabdominal ultrasound approach was used in assessing the fetal head position by placing the covered transducer in transverse probe orientation at the suprapubic region of the maternal abdomen. Confirmation of cephalic presentation was made before proceeding with the study. Scans were performed in the absence of uterine contractions by obtaining an axial view of the fetal head. In the axial view, midline intracranial structures, including the thalami, falx cerebri, cavum septum pellucidi and the cerebellar hemisphere, served as anatomical landmarks for determining the occipital region of the fetal head. Anterior and posterior cranial structures such as the orbits, nasal bridge, and cervical spine were also used for the identification of direct posterior position. The classification of the fetal head position was therefore determined by following guidelines of the conventional probe orientation for transverse sonograms. Fig. 1, Fig. 2, and Fig. 3 show the orientations for occiput posterior positions.

\section{Statistical analysis}

The data was double-entered into Microsoft Excel Spread Sheet and analyzed with XLSTAT version 2015.6 (Addinsoft, Brooklyn, NY, USA).

The main outcome variable, i.e. fetal head position, was categorized into eight possible options using the $360^{\circ}$ of a circle with a $45^{\circ}$ interval as follows: left occiput anterior (LOA, $45^{\circ}$ ), left occiput transverse (LOT, 90 ${ }^{\circ}$ ), left occiput 


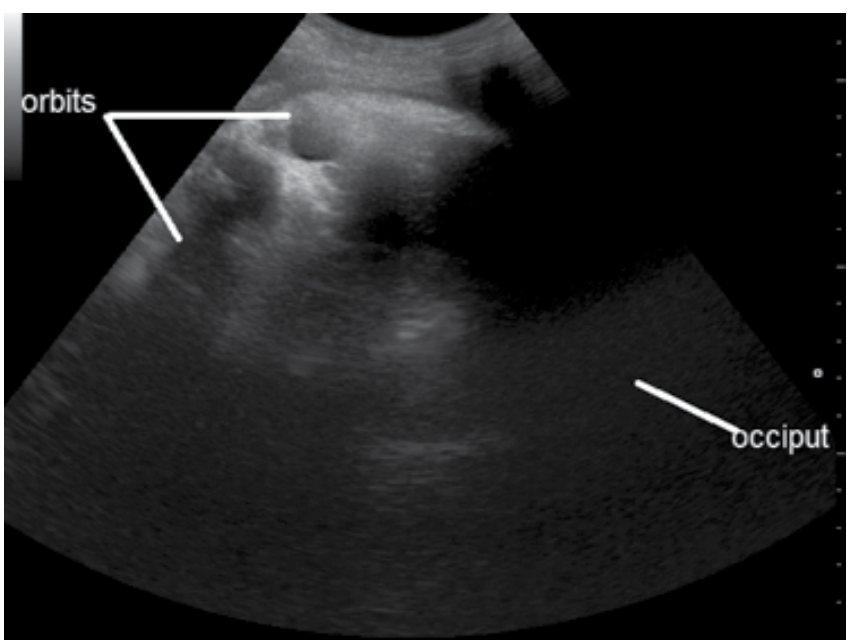

Fig. 1. Left occiput posterior (LOP) position

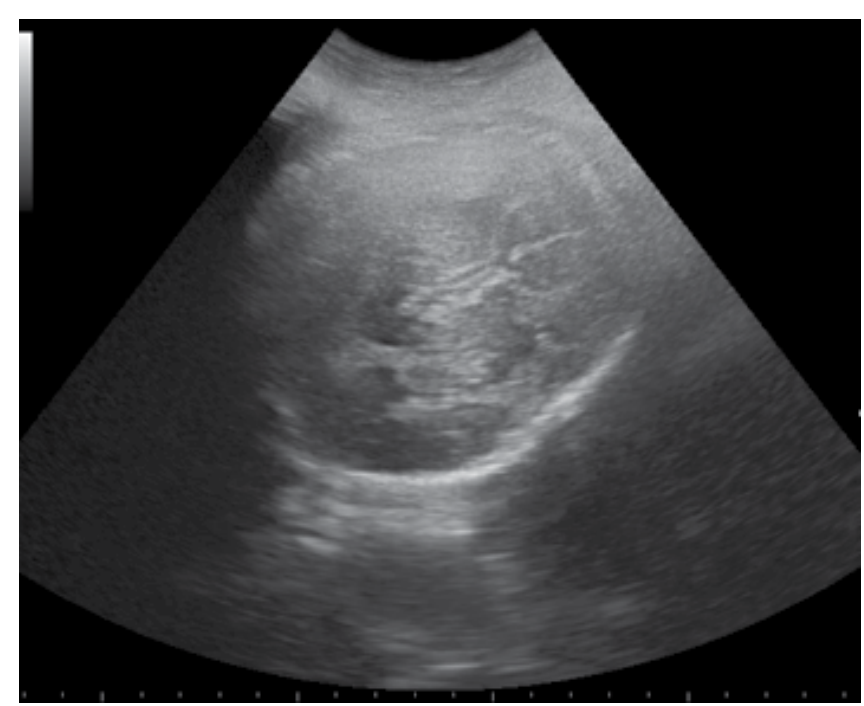

Fig. 2. Right occiput posterior (ROP) position

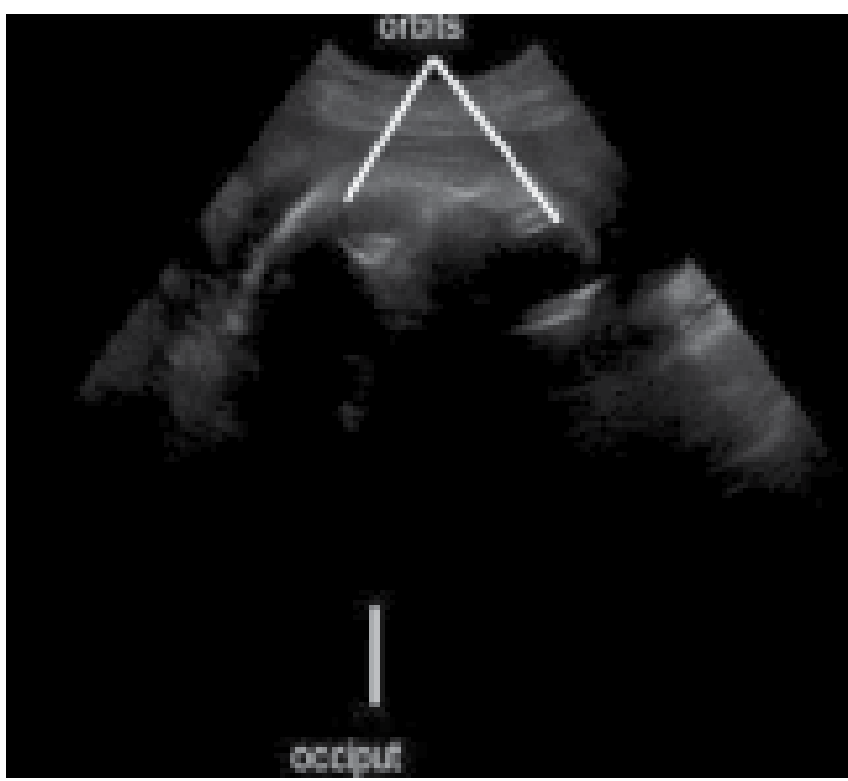

Fig. 3. Direct occiput posterior (DOP) position posterior ( $\mathrm{LOP}, 135^{\circ}$ ), direct occiput posterior (DOP, $180^{\circ}$ ), right occiput posterior (ROP, $225^{\circ}$ ), right occiput transverse $\left(\mathrm{ROT}, 270^{\circ}\right)$, right occiput anterior $\left(\mathrm{ROA}, 315^{\circ}\right)$, and direct occiput anterior (DOA, 360 $)$.

The level of agreement between ultrasound and digital VE was analyzed by Cohen's kappa statistics.

The study was approved by the Committee on Human Research, Publications and Ethics of Kwame Nkrumah University of Science and Technology and Komfo Anokye Teaching Hospital, and informed consent was obtained from all study participants.

\section{Results}

In total, results were obtained from 196 participants as presented in Tab. 1. The ages ranged from 18 to 39 years with a mean of 26.8 years (standard deviation 4.9 years). Nearly half (47\%) of the women were primiparas. The average gestational age of the participants was 39 weeks 4 days. At the time of the ultrasound examination, $36 \%$ of the women had ruptured membranes, and labor was being augmented in about $14 \%$ of the participants.

The determination of the fetal head position was obtainable with ultrasound in all participants, but only in 134 participants with digital VE. In the remaining 62 cases $(32 \%)$, the clinicians could not determine the fetal head position during digital VE. Of this group, 37 cases were in transverse positions $(60 \%)$ and 16 in posterior positions $(26 \%)$. In the 134 fetal head positions determined by digital VE, the agreement with ultrasound was moderate (kappa $=0.405)$. However, the overall agreement for the 196 participants was low (kappa $=0.21)$ as shown in Tab. 2.

Out of the 196 participants, ultrasound obtained 70 occiput posterior positions, including ROP, LOP and DOP positions. Ultrasound and digital VE agreed on the occiput posterior position in 14 out of the $70(20 \%)$, and disagreed in 56 out of the $70(80 \%)$ cases. However, they both agreed that 112 fetuses were not in occiput posterior positions. This yielded a between-method percentage agreement of $64 \%$ on occiput posterior positions, and a kappa value of 0.1 (Tab. 2). Agreement on the transverse occiput position is also presented in Tab. 2.

Out of the 196 participants, 71 had ruptured membranes. The number of occiput posterior positions obtained by ultrasound in these 71 women was 30 , but digital VE agreed with this in only 7 participants. On the other hand, digital VE obtained occiput posterior positions in 7 out of the 71 women with ruptured membranes, on which ultrasound disagreed. However, both examinations agreed that 34 participants in the ruptured membrane group were not in occiput posterior positions. Tab. 3 shows details on agreement between ultrasound and digital VE in the population with ruptured membranes versus intact membranes. 
Tab. 1. Reproductive characteristics of the women

\begin{tabular}{|c|c|c|}
\hline Variables & Number $^{\mathrm{a}}$ & Percentage (\%) \\
\hline \multicolumn{3}{|l|}{ Age group (years) } \\
\hline$<20$ & 9 & 4.5 \\
\hline $20-29$ & 134 & 68.0 \\
\hline $30-39$ & 55 & 27.5 \\
\hline Mean $\pm S D$ (years) & $26.8 \pm 4.9$ & \\
\hline Body mass index $\left(\mathrm{kg} / \mathrm{m}^{2}\right)$ & $27.8 \pm 3.5$ & \\
\hline \multicolumn{3}{|l|}{ Parity } \\
\hline Nulliparous & 92 & 47.0 \\
\hline Primiparous & 43 & 22.0 \\
\hline Multiparous & 61 & 31.0 \\
\hline Mean gestational age $\pm S D$ (weeks) & $39.6 \pm 1.07$ & \\
\hline \multicolumn{3}{|l|}{ Ruptured membranes } \\
\hline Yes & 69 & 36.0 \\
\hline No & 127 & 64.5 \\
\hline \multicolumn{3}{|l|}{ Fetal head positions (ultrasound) } \\
\hline Left occiput anterior & 21 & 10.7 \\
\hline Left occiput transverse & 60 & 30.6 \\
\hline Left occiput posterior & 35 & 17.9 \\
\hline Direct occiput posterior & 5 & 2.6 \\
\hline Right occiput posterior & 30 & 15.3 \\
\hline Right occiput transverse & 33 & 16.9 \\
\hline Right occiput anterior & 12 & 6.1 \\
\hline $\begin{array}{l}\text { a Number unless otherwise indicate } \\
\text { SD - standard deviation }\end{array}$ & & \\
\hline
\end{tabular}

\section{Discussion}

The purpose of the study was to compare intrapartum ultrasound and digital VE in the assessment of the fetal head position in black African women in the first stage of labor.

The occiput transverse position was the commonest fetal head position in this study population (47\%), followed by the occiput posterior position (36\%) and then the occiput anterior position (17\%). The high rate of the occiput transverse position agrees with Ahmad et al. ${ }^{(10)}$ whose study comprised $5 \%$ of blacks, $23 \%$ of Asians and over $50 \%$ of whites. However, our population had the highest percentage of occiput transverse positions in the first stage of labor. Again, the $36 \%$ of the occiput posterior positions is within the $30 \%$ reported by studies conducted in other populations ${ }^{(11)}$.

In a third of the study population, digital VE could not determine the fetal head position. This is comparable to similar studies conducted in other geographical locations, which reported up to $60 \%$ difficulty in determining the fetal head position with digital VE in the first stage of labor. While Souka et al. ${ }^{(12)}$ attributed this difficulty to occiput posterior positions, the dominant position in such cases in our study was occiput transverse.

The overall agreement between ultrasound and digital VE in our study was low (kappa $=0.2)$ and comparable to

Tab. 2. Kappa table of agreement between Ultrasound and Digital VE on fetal head position

\begin{tabular}{|c|c|c|c|c|}
\hline \multicolumn{5}{|c|}{ Overall agreement in the range of $45^{\circ}$} \\
\hline \multicolumn{5}{|c|}{ Ultrasound (+)/(-) } \\
\hline \multirow[t]{6}{*}{ Digital VE (+)/(-) } & & + & - & Total: \\
\hline & + & $(n: 68)$ & $(n: 128)$ & $(n: 196)$ \\
\hline & - & $(n: 0)$ & $(n: 66)$ & $(n: 66)$ \\
\hline & Total: & 68 & 194 & 262 \\
\hline & Observed agreements \% & $134(51.15 \%)$ & $\begin{array}{c}\text { Kappa }=0.211 ; 95 \% \mathrm{Cl}: \\
\text { From } 0.151 \text { to } 0.271 \\
\end{array}$ & \\
\hline & Agreements expected by chance \%: & $99.7(38.07)$ & & \\
\hline \multicolumn{5}{|c|}{ Agreement on occiput posterior positions } \\
\hline \multicolumn{5}{|c|}{ Ultrasound (+)/(-) } \\
\hline \multirow[t]{6}{*}{ Digital VE (+)/(-) } & & + & - & Total: \\
\hline & + & $(n: 14)$ & $(n: 56)$ & $(n: 70)$ \\
\hline & - & $(n: 14)$ & $(n: 112)$ & $(n: 126)$ \\
\hline & Total: & $(n: 28)$ & $(n: 168)$ & (n: 196) \\
\hline & Observed agreements \% & $126(64.29 \%)$ & $\begin{array}{c}\text { Kappa }=0.103 ; 95 \% \mathrm{Cl}: \\
\text { From }-0.022 \text { to } 0.227\end{array}$ & \\
\hline & Agreements expected by chance \%: & $118.0(60.209 \%)$ & & \\
\hline \multicolumn{5}{|c|}{ Agreement on transverse positions } \\
\hline \multicolumn{5}{|c|}{ Ultrasound (+)/(-) } \\
\hline \multirow[t]{6}{*}{ Digital VE (+)/(-) } & & + & - & Total: \\
\hline & + & $(n: 23)$ & $(n: 70)$ & $(n: 93)$ \\
\hline & - & $(n: 23)$ & $(n: 80)$ & (n: 103) \\
\hline & Total: & $(n: 46)$ & $(n: 150)$ & $(n: 196)$ \\
\hline & Observed agreements \% & 103 (52.55\%) & $\begin{array}{c}\text { Kappa }=0.02595 \% \mathrm{Cl}: \\
\text { From }-0.182 \text { to } 0.057\end{array}$ & \\
\hline & Agreements expected by chance \%: & $100.7(51.35 \%)$ & & \\
\hline
\end{tabular}


Tab. 3. Kappa table of agreement on OP positions in the sub-group with ruptured and intact membranes

\begin{tabular}{|c|c|c|c|c|}
\hline \multicolumn{5}{|c|}{ Occiput posterior position with ruptured membranes } \\
\hline \multicolumn{5}{|c|}{ Ultrasound (+)/(-) } \\
\hline Digital VE (+)/(-) & & + & - & Total: \\
\hline & + & $(n: 7)$ & $(n: 23)$ & $(n: 30)$ \\
\hline & - & $(n: 7)$ & $(n: 34)$ & $(n: 41)$ \\
\hline & Total: & $(n: 14)$ & $(n: 57)$ & $(n: 71)$ \\
\hline & Observed agreements \% & $41(57.75 \%)$ & $\begin{array}{c}\text { Kappa }=0.067 ; 95 \% \mathrm{Cl}: \\
\text { From }-0.137 \text { to } 0.272 \\
\end{array}$ & \\
\hline & Agreements expected by chance $\%$ : & $38.8(54.69 \%)$ & & \\
\hline \multicolumn{5}{|c|}{ Occiput posterior position with intact membranes } \\
\hline \multicolumn{5}{|c|}{ Ultrasound (+)/(-) } \\
\hline \multirow[t]{6}{*}{ Digital VE (+)/(-) } & & + & - & Total: \\
\hline & + & $(n: 7)$ & $(n: 33)$ & $(n: 40)$ \\
\hline & - & $(n: 9)$ & $(n: 76)$ & $(n: 85)$ \\
\hline & Total: & $(n: 16)$ & $(n: 109)$ & $(n: 125)$ \\
\hline & Observed agreements $\%$ & $83(66.40 \%)$ & $\begin{array}{c}\text { Kappa }=0.082 ; 95 \% \mathrm{Cl}: \\
\text { From }-0.077 \text { to } 0.241\end{array}$ & \\
\hline & Agreements expected by chance \%: & $79.2(63.39 \%)$ & & \\
\hline
\end{tabular}

studies by Sherer et al. ${ }^{(13)}$, who obtained a kappa value of 0.12 in their American population, and Shetty et al. ${ }^{14}$, who obtained a value of 0.15 in an Indian population. However, a moderate kappa concordance of 0.4 was obtained after removing cases that could not be determined by VE, which is also comparable to the moderate agreement obtained by Souka et al. ${ }^{12}$ after they had removed the same variable.

Earlier studies by Souka et al. ${ }^{(12)}$ and Shetty et al..$^{(14)}$ had observed that the detection of occiput posterior position by digital VE was more difficult than the occiput anterior position, but they provided no statistical analysis for the agreement on the occiput posterior position. Hence, as further investigation, our study analyzed the between-method agreement on the occiput posterior position, which was very low (kappa $=0.1)$. This confirms the extreme difficulty associated with detecting the occiput posterior position with digital VE. We further identified that the transverse position was much more difficult to determine with digital VE (kappa $=0.02$ ) than the posterior position in our study population.

In addition, the study also found that about $85 \%$ of fetal head positions that could not be determined by digital VE were transverse and posterior positions, which confirms that digital VE has difficulty in detecting malpositions. The implications of the difficulty in detecting occiput posterior and transverse positions in the first stage of labor were beyond the scope of our study design. However, Choi et al. ${ }^{(15)}$ reported that occiput posterior positions in the first stage of labor had higher percentage of cesarean sections than first stage occiput anterior positions. Further research is therefore needed in the black African population to establish the relationship between mode of delivery and first stage occiput positions. In a related subject, the administration of oxytocin has been reported as an influence on the rotation of occiput posterior position ${ }^{(16)}$, which would make the use of ultrasound in confirming fetal head position a useful technology to employ when considering labor augmentation.

Regarding our hypothesized view on the possible influence of ruptured membranes on agreement, no statistically significant influence was obtained in our study. It therefore suggests that ruptured membranes do not improve the accuracy of digital VE.

The major limitation of our study was that it had not been designed to examine participants from the onset of labor to delivery, which could have identified the relationship between mode of delivery and the first stage occiput position.

\section{Conclusions}

In conclusion, this study suggests poor agreement between ultrasound and digital VE on the occiput posterior position in black African women who were in the first stage of labor. Again, over $85 \%$ of fetal head positions that could not be determined by digital VE were occiput transverse and posterior positions. This shows that Digital VE has difficulty in detecting malpositions, with no significant influence of intact or ruptured membranes. Ultrasound is therefore more useful than digital VE whenever malposition is suspected in the first stage of labor.

\section{Conflict of interest}

Authors do not report any financial or personal connections with other persons or organizations, which might negatively affect the contents of this publication and/or claim authorship rights to this publication. 


\section{References}

1. Ponkey SE, Cohen AP, Heffner LJ, Lieberman E: Persistent fetal occiput posterior position: obstetric outcomes. Obstet Gynecol 2003; 101: 915-920.

2. Fitzpatrick M, McQuillan K, O’Herlihy C: Influence of persistent occiput posterior position on delivery outcome. Obstet Gynecol 2001; 98: 1027-1031.

3. Cheng YW, Shaffer BL, Caughey AB: Associated factors and outcomes of persistent occiput posterior position: a retrospective cohort study from 1976 to 2001. J Maternal Fetal Neonatal Med 2006; 19: 563-568.

4. Pearl ML, Roberts JM, Laros RK, Hurd WW: Vaginal delivery from the persistent occiput posterior position. Influence on maternal and neonatal morbidity. J Reprod Med 1993; 38: 955-961.

5. Wiafe YA, Whitehead B, Venables H, Nakua EK: The effectiveness of intrapartum ultrasonography in assessing cervical dilatation, head station and position: a systematic review and meta-analysis. Ultrasound 2016; 24: 222-232.

6. Handa VL, Lockhart ME, Fielding JR, Bradley CS, Brubaker L, Cundiff GW et al.: Racial differences in pelvic anatomy by magnetic resonance imaging. Obstet Gynecol 2008; 111: 914-920.

7. Hoyte L, Thomas J, Foster RT, Shott S, Jakab M, Weidner AC: Racial differences in pelvic morphology among asymptomatic nulliparous women as seen on three-dimensional magnetic resonance images. Am J Obstet Gynecol 2005; 193: 2035-2040.

8. Betti L, Manica A: Human variation in the shape of the birth canal is significant and geographically structured. Proc Biol Sci 2018; 285: 20181807.

9. Shaffer BL, Cheng YW, Vargas JE, Laros RK Jr, Caughey AB: Face presentation: predictors and delivery route. Am J Obstet Gynecol 2006; 194: 10-12.
10. Ahmad A, Webb SS, Early B, Sitch A, Khan K, MacArthur C: Association between fetal position at onset of labor and mode of delivery: a prospective cohort study. Ultrasound Obstet Gynecol 2014; 43: 176-182.

11. Malvasi A, Tinelli A, Barbera A, Eggebø TM, Mynbaev OA, Bochicchio M et al.: Occiput posterior position diagnosis: vaginal examination or intrapartum sonography? A clinical review. J Matern Fetal Neonatal Med 2014; 27: 520-526.

12. Souka AP, Haritos T, Basayiannis K, Noikokyri N, Antsaklis A: Intrapartum ultrasound for the examination of the fetal head position in normal and obstructed labor. J Matern Fetal Neonatal Med 2003; 13: 59-63.

13. Sherer DM, Miodovnik M, Bradley KS, Langer O: Intrapartum fetal head position I: comparison between transvaginal digital examination and transabdominal ultrasound assessment during the active stage of labor. Ultrasound Obstet Gynecol 2002; 19: 258-263.

14. Shetty J, Aahir V, Pandey D, Adiga P, Kamath A: Fetal head position during the first stage of labor: comparison between vaginal examination and transabdominal ultrasound. ISRN Obstet Gynecol 2014; 2014 : 314617 .

15. Choi SK, Park YG, Lee DH, Ko HS, Park IY, Shin JC: Sonographic assessment of fetal occiput position during labor for the prediction of labor dystocia and perinatal outcomes. J Matern Fetal Neonatal Med 2016; 29: 3988-3992.

16. Blanc-Petitjean P, Le Ray C, Lepleux F, De La Calle A, Dreyfus M, Chantry AA: Factors affecting rotation of occiput posterior position during the first stage of labor. J Gynecol Obstet Hum Reprod 2018; 47: 119-125. 